\title{
Prevalencia de Escherichia coli-ST131 productoras de BLEE en aislados de bacteriemias desde 2009 al 2018
}

\author{
Zurita, Jeannete ${ }^{1,2,3 *}$; Sevillano, Gabriela ${ }^{3}$; Paz y Miño, Arianne ${ }^{3}$; Haro, Nathalín \\ ${ }^{1}$ Hospital Vozandes, Quito, Ecuador. \\ 2 Pontificia Universidad Católica del Ecuador, Facultad de Medicina. Quito, Ecuador. \\ ${ }^{3}$ Unidad de Investigaciones en Biomedicina. Zurita \& Zurita Laboratorios, Quito, Ecuador. \\ e-mail: jzurita@zuritalaboratorios.com
}

\begin{abstract}
Palabras clave: Bacteriemias, bla ${ }_{C T X-M^{\prime}} B L E E$, E. coli-ST131.

INTRODUCCIÓN: La secuencia tipo Escherichia coli 131 (E. coli-ST131) se identificó por primera vez entre los aislados productores de $\beta$-lactamasas de espectro extendido (BLEE) en Asia, Europa y Norteamérica en el 2008. [1] Este clon ha emergido rápidamente a nivel mundial hasta llegar a ser un importante patógeno extra-intestinal, siendo el más predominante gracias a su capacidad de adaptación. [2]
\end{abstract}

OBJETIV0: Identificar la secuencia tipo (ST) y los genes bla $a_{C T X-M-15}$ de E. coli-BLEE en cepas recolectadas de bacteriemias en un período de 10 años.

MATERIALES Y MÉTODOS: De la colección de microorganismos congelados en el Hospital Vozandes Quito, se seleccionaron 147 E. coli-BLEE aisladas de bacteriemias. Durante este período se aislaron un total de 509 E. coli (147/509; $28,8 \%$ ) de hemocultivos, que fueron procesados con el sistema Bactec 9120 y la identificación bacteriana se realizó con el sistema Vitek2. Los datos demográficos fueron obtenidos del software WHONET. Una vez descongeladas las cepas, se identificaron las secuencias tipo (ST) y los genes implicados en la resistencia mediante PCR y secuenciación.

RESULTADOS: De las 147 E. coli-BLEE, 60\% (88/147) albergaban el gen bla $a_{C T X-M-15}$ y $59.17 \%$ $(87 / 147 ; 59,17 \%)$ pertenecieron al clon ST131, el mismo que no aparece sino hasta el año
$2010(12,5 \%)$, a partir del cual se incrementó significativamente hasta el año 2018 (58\%). La prevalencia de E. coli-BLEE aumentó gradualmente desde el 2009 (9,43\%) hasta 2018 $(27,9 \%)$, con la mayor prevalencia en el 2014 $(40 \%)$.

CONCLUSIONES: No se evidenció la presencia del clon E. coli ST131 antes del 2009. Una mayor prevalencia del clon ST131 junto con bla ${ }_{C T X-M-15}$ se observó en estos 10 años, lo cual podría indicar que este clon es el responsable de la diseminación de bla ${ }_{C T X-M-15^{5}}$ La persistencia de este clon en estos 10 años, demuestra su capacidad de adaptación para mantenerse en el tiempo. Ecuador no está fuera del estallido emergente de ST131 que se ha producido en los últimos años a nivel mundial, lo que demuestra la importancia de la monitorización del clon para proporcionar a las autoridades de salud pública una mejor información para ayudar a combatir este clon.

\section{REFERENCIAS:}

[1] Nicolas-Chanoine $\mathrm{M}$, Blanco J, LeflonGuibout V, Demarty R, Alonso M, Caniça M, et al. Intercontinental emergence of Escherichia coli clone 025:H4-ST131 producing CTX-M-15. J Antimicrob Chemother. 2008; 61(2): 273-281.

[2] Mathers AJ, Peirano G, Pitout JDD. The role of epidemic resistance plasmids and international high- risk clones in the spread of multidrugresistant Enterobacteriaceae. Clin Microbiol Rev. 2015 ; 28(3): 565-591. 